\title{
Beyond Delivery Method: Does the Big Five Matter in Accounting Performance
}

\author{
Michelle M. Kusaila \\ Central Connecticut State University \\ Mary M. McCarthy \\ Central Connecticut State University \\ Lawrence Grasso \\ Central Connecticut State University
}

Using the Big Five personality trait model this study is the first to explore the consistency of personality traits and the impact on accounting student performance in online, hybrid, and face-to-face education delivery formats. Results confirm GPA as a strong predictor of future performance, as none of the Big Five traits were significant to the final grade. The lack of significance of the Big Five and continued support for GPA as a strong performance predictor in any delivery modes confirms good performing students perform well regardless of delivery mode.

\section{INTRODUCTION}

In the 2013 AACSB questionnaire, there was a $43 \%$ increase in the number of accredited schools offering fully online courses (Nelson, 2013). As technology dramatically changed all instructional delivery methods, understanding how or if non-cognitive factors such as personality traits correlate to academic performance in today's educational environments is important. This study explores the use of the Big Five to identify relationships between broad personality traits and academic performance across online, hybrid, and traditional educational delivery formats in upper-division accounting students. The Big Five looks at the dichotomies between five items: openness/closedness to new experiences, conscientiousness/lack of direction, extraversion/introversion, agreeableness/antagonism, and neuroticism/emotional stability. The problematic conditions that lead to this study are hybrid and online delivery modes are a part of today's higher education model, but little research looks at individual learning antecedents in various delivery methods that are central to performance. This study uses regression analysis to look at the relationship between personality traits and performance in upperdivision accounting courses.

The purpose of this study is to examine the relationship between personality traits of upper-division accounting students and class performance using the Big Five. Personality traits are considered to precede learning. This premise assumes that "behaviors that maximize [student] learning are contingent on the 
delivery method" (Varella, Carter, \& Michel, 2012, p. 209). Consistent with Kolb's (2014) theory of experiential learning in that understanding personality type and ways to learn leads to self-awareness and openness to learn new ways. As course delivery methods adapt to the $21^{\text {st }}$-century learning environment, it is important to understand if different delivery methods have different performance outcomes for various personality traits. There is growing research on various delivery methods, and academic performance measured in a variety of ways (Allen \& Seaman, 2017; Chen, Jones, \& Moreland, 2013; U.S. Department of Education, 2009). Based on a review of the extant literature there is little research on the personality of accounting students and performance outcomes in today's alternative learning environments. Knowing how or if different personalities traits can affect student performance within different course deliveries applied as a further understanding of what type of students should succeed in an alternative delivery environment and what students may need an introductory course or an early alert to possibly not being successful in a class that needs more self-motivation. This paper will next outline literature on personality and academic performance. First, we define the three delivery modes. Second, we introduce the Big Five traits. Third, we provide some background on academic performance measures. Next, we discuss the central research question, methodology, and results. Finally, a discussion of the research findings and suggestions for future research.

\section{LITERATURE REVIEW}

\section{Delivery Methods}

Distance learning evolved from its beginnings in the 1800's where shorthand courses conducted by mail; then courses were delivered through instructional media, online education, and next open universities (Colorado \& Eberle, 2010). Today 98\% of United States individuals have access to the highspeed broadband internet (U.S. Department of Commerce, 2013). Broadband internet paved the way for distance education to evolve into an on-demand format with synchronous or asynchronous communication between students and instructors and immediate turnaround time from earlier distance learning formats. Alternative educational delivery have updated from the 1800 's for the $21^{\text {st }}$ century. Today's university learning incorporates some web facilitation either in the classroom, through a learning management system (LMS), an entirely online class, or some combination of these traits in a hybrid delivery method.

While online education is the modern form of distance learning, and online course enrollment is ever increasing, not all college and university faculty have accepted the effectiveness of online education. Early studies of distance learning (U.S. Department of Education, 2009) concluded that it was not statically different from traditional face-to-face classroom format regarding learning effectiveness. Current studies conclude student performance in online education, just like distance learning is not significantly different from the face-to-face classroom for undergraduate, graduate, and professional education (Allen \& Seaman, 2017; U.S. Department of Education, 2009). The U.S. Department of Education (2009) report finds hybrid students show better performance than both online and face-to-face but believe the increased performance in the hybrid course was due to additional time spent on task, not delivery format. More recent studies (Chen, Jones, \& Moreland, 2013) report conflicting results comparing face-to-face education with hybrid delivery and face-to-face with online delivery methods.

Allen and Seaman (2017) define a hybrid course as one with $30 \%$ to $79 \%$ of course content delivered online. Hybrid delivery has a reduced number of face-to-face assigned meeting times as a substantial amount of content is delivered online, prerecorded lectures are available on demand in the LMS, course assignments and other course design features are conducted virtually, blending a reduced amount of faceto-face meeting times to facilitate learning. There are broad uses of the term hybrid in the literature, from simple to extensive use of an LMS. For this study, contact hours was used to define the delivery method. An online course for this study delivers all content online and has no face-to-face meetings. A traditional course would meet $100 \%$ of the time face-to-face with web enhancements through the LMS such as the posted syllabus, assignments, and supplemental resource, but does not replace face-to-face meeting times; also known as a web-facilitated class in the literature. As educational delivery methods update for the $21^{\text {st }}$ 
century, current research needs to advance conditions that increase the effectiveness of online and hybrid teaching to see if it is consistent with traditional delivery formats.

\section{Personality Traits}

To understand the effectiveness of various delivery formats is to look at student personality traits. The literature defines traits as relatively stable patterns of behavior, thought, or emotions over time (Jung, 1998; Taggar \& Parkinson, 2007). This fixed nature leverages personality trait tests to be applicable in many instances, so personality testing does not need to be repeatedly done to identify relationships between personality and other factors. Measuring an individual's traits are not measuring an individual's intelligence but rather identifying ways individuals act within their environment, occupation, and classrooms. While there is not an agreed upon set of traits, there are many widely accepted instruments such as the Big Five or the Five Factor Model (FFM) to measure an individual's traits (Poropat, 2009; Tidwell, et al., 2010; Anitsal et al., 2010; Anitsal et al., 2008).

The Big Five uses five measures of personality: openness, conscientiousness, extraversion, agreeableness, neuroticism (McCrae \& Costa, 1989). While personality using the Myers-Briggs instrument has been used in the literature, the Big Five is advantageous as it uses scales for each measure, rather than a cutoff. Commonly referred to as the acronym OCEAN. The instrument uses short individually reflective questions "based on the factor analysis of Allport and Odbert's (1936) pool of 17,853 personality adjectives" (Tidwell \& Southard, 2010, p. 71). Personality traits derived from a lexical model where personality terms found in the natural language were grouped with similar terms until ultimately ended at five broad terms. The Big Five used today refined by McCrae \& Costa (1989) who used five-factor theory to explain the Big Five taxonomy to cover most aspects of personality broadly. While the Big Five cannot capture all variations of human behavior, it aims to identify broad individual trait patterns. The choice of the Abridged Big Five model is not that it is superior to other instruments. However, rather build upon a personality framework that has been repeatedly validated in many different disciplines (Varella, et al., 2012; Anitsal et al., 2010; Anitsal et al., 2008; Poropat, 2009).

There has been a greater emphasis on "the nature of being an accountant" (Wheeler, 2001, p. 125). This applies to the whole person who is an accountant; how they work within a group setting, their interaction with clients, communication of complex financial information to non-accountants, and ethical decisions within the profession. Many of these factors involve personality characteristics, and only a small fraction of the published personality trait research looks at professional accountants and accounting students. Explaining these differences can be particularly important in explaining predicted behaviors and personality traits to better "understand how accountants interact with their environment and influence accounting outcomes" (Taggar \& Parkinson, 2007, p. 122). Accounting education is an applied subject (Xu \& Jaggars, 2014) and the profession is continually changing to meet changing societal needs, faculty recognize this and continue to prepare students best.

Extraversion or introversion the opposing trait is central to how individuals orient themselves about their natural environment (Jung, 1976). In trait theory, extraversion is not defined the same as in popular culture. Jung (1976) defined introverted individuals as thought-oriented. These individuals prefer a depth of knowledge through ideas and reflection alone. Extraverted individuals represent a reverse relationship where they get their energy from action; they prefer to act, reflect, and then act again (Jung, 1976). The nature of online education is "learning occurs primarily through autonomous and introspective efforts rather than through the vivid exchanges characterizing traditional settings" (Varella et al., 2012, p. 213). Harrington and Lofredo (2010) and Antisal et al. (2008) found introverted individuals' preference to reflect alone, act, and reflect. Fallan and Opstad (2014) found extraverted management accounting students performed better, but did not look at different delivery modes. Varella et al. (2012) found no statistical difference between online and traditional students' performance and Tidwell et al. (2010) noted a positive but not significant relationship between extraversion and performance but no difference between delivery methods.

Conscientiousness is the most consistent personality trait associated with a positive academic performance from K-12 and into higher education (Poropat, 2009; Farrington et al., 2012; Poropat, 2009; 
Varella et al., 2012; Tidwell \& Southard, 2010). Conscientiousness is not a measure of intelligence but rather the sustained tenacity one is willing to work at a task. The trait has been shown to have signs of success in high school and earnings nine years into an individuals career (Farrington et al., 2012). "Conscientiousness tends to show signs of dependability, thoroughness, and responsibility [... and] scholastic characteristics [...] such as hard work, achievement-orientation, responsibility and perseverance (Tidwell et al., 2010, p. 71). Current research relates consciousness to grit. Farrington et al. (2012) say, "grit should also be understood as a stable personality trait, perhaps a mistakenly overlooked facet of consciousness" (p. 24). Antisal et al. (2010) oppose this view and assert that it is work drive and general intelligence that has a stronger correlation than any of the Big Five factors. Current research links conscientiousness consistently to academic and occupational performance, but the research on delivery methods is inconsistent. Tidwell and Southard (2010) found hybrid student's outperformed online and traditional students while Varella et al. (2012) found a significant relationship in online students' performance and no significant relationship in traditional face-to-face delivery. Antisal et al. (2008) found traditional students to rate higher in conscientiousness but did not relate this to performance.

What are the non-cognitive factors that set students apart from taking those good grades and translating them into consistent academic performance and later success in the workplace? One factor that Farrington et al. (2012) note is grit; "grit behaves like an inherent character trait [...] it is stable over time-and perhaps is most fruitfully understood in the context of the 'Big Five' personality traits" (p. 24). So what students lack in achievements through standardized testing they can make up for in grit. Grit is individual to each student and is measured as a student's perseverance when working on a challenging assignment. This academic quality behavior "includes intensity, direction, and duration a student is engaged and focused in pursuit of academic goals, despite obstacles, setbacks, and distractions" (Farrington et al., 2012, p. 20). Recent literature shows these non-cognitive factors are being shown to have more of an effect than just on academic performance alone. Non-cognitive factors, such as grit, can suggest college readiness and also career readiness. Grit is measured by the consciousness factor using the Big Five.

Accounting as a choice of major can be closely associated with an occupational choice as the study is an application of the practice. Accounting students are shown to have personality characteristics that meet traditional society occupational stereotypes scoring highest in conformity (Pringle, Dubose \& Yankey, 2010). Holland (1997) believed that people choose their job based on their individual perceived fit within the work environment. Agreeableness, another measure of the Big Five, can be related to conformity and cooperation with the learning process. Occupational personality trait research shows students enter into a major based on their perceived conformity with the later profession (Holland, 1997; Pringle, Dubose \& Yankey, 2010). Accounting majors, when compared to other business majors, tend to show higher levels of agreeableness and personality characteristics that meet traditional society occupational stereotypes (Pringle, Dubose \& Yankey, 2010). This is in line with Holland's (1997) vocational choice theory that people enter professions where there is a perceived personality fit within the chosen work environment. Antisal et al. (2008) found the traditional student to be more agreeable overall but did not look at the interaction with the performance. Poropat (2009) in a meta-analysis of Big Five and academic performance links agreeableness with cooperation with teacher instructions but has limited positive impact on positive student performance.

In a university where online education is just beginning, students would need to be open to new experience to enroll in an online course and succeed. These students who are open to new experiences would rate higher on the openness scale. It is those students who are willing to try new experiences with an open mind in many aspects of life who will give a new delivery format a chance. Poropat (2009) identified openness to be positively associated with the approach to learning, representing "the ideal student" (p. 13). Antisal et al. (2008) found no differences between openness and delivery method but did not look at performance. Tidwell and Southard (2010) noted a positive relationship between openness and performance and that hybrid student outperformed online and traditional students; this is consistent with the U.S. meta-analysis (U.S. Department of Education, 2009). 


\section{Performance Measures}

There are various performance measures used within the literature to determine student performance including completion rates, student evaluations, before and after online learning attitudes, final grade, test grades, time spent on task, student self reports, and many others (Poropat, 2009; Seiver \& Troja, 2014; U.S. Department of Education, 2009; Xu \& Jaggars, 2014). Prior research shows that student scores such as grades, grade point average (GPA) or class rank are the best predictors of college performance and graduation (Farrington et al., 2012; Huh, Jin, Lee, \& Yoo, 2010). These performance measures go beyond college performance and graduation. Farrington et al. (2012) report a strong relationship between high school grades and earnings nine years post high school, controlling for educational achievements, for adolescent populations. Student grades and the combined effect of earned grades, and GPA are determining factors in predicting possible future performance.

GPA used as a performance measure has its limitations. There are problems associated with grade inflation that can impact comparing one study against another (Poropat, 2009). Some studies control for grade inflation by comparing the same instructor across different course sections to ensure grade similarity. There is a growing body of literature focusing on standardized test scores not being strong indicators of college success, performance, or completion (Farrington et al., 2012) where GPA has shown stronger positive correlation to future success. However, if it is more than just performing well on a standardized test, and consistently performing well in the classroom, educators need to understand what other factors grades capture in addition to content mastery.

Grades, a typical performance measure, measure content knowledge and academic skills, but grades also measure other non-cognitive factors such as personality traits. Farrington et al. (2012) noted in adolescents that these non-cognitive factors identify students who consistently perform well in rigorous coursework and then later success in the workplace. Farrington et al. (2012) provide a critical review of research that speculates into what other factors grades measure for positive academic performance.

While test scores measure both content knowledge and academic skills, grades a subcomponent of GPA measure content knowledge, academic skills, and non-cognitive factors. It is grades that are shown to have the additional relationship with continued increased positive performance and are used as the performance measure in this study. Understanding the factors that correlate with academic performance into future work performance can be important to mentor students to perform better in the long term. In the next section, we discuss the relationship between personality and academic performance along with proposed central research question.

\section{RESEARCH QUESTION}

\section{Personality and Academic Performance}

Business students, in general, are known to have different personality traits than other students such as liberal arts majors (Wheeler, 2001; Taggar \& Parkinson, 2007). Daisley (2011) compared businessstudents' personality traits to that of the general public using the Myers-Briggs Type Indicator (MBTI). Results were that business students, as measured by over 1,900 MBA students, generally scored 1.5 to 2.0 times more on the ISTJ and ESTJ (Introverted/Extraverted - Sensing - Thinking - Judging) personality types, than the general public. This is consistent with Wheeler (2001) and Taggar and Parkinson (2007) who also classify accountants primarily as STJ on the MBTI. Taggar and Parkinson (2007) found that the extraversion-introversion indicator was split depending on an individual's firm location and size. This strong preference for business, and more specifically accounting students to be drawn to the I/E-STJ personality type shows that there is a skewed population within the business community. Business students and more specifically accounting students' personality traits should be looked at individually to identify unique relationships. Fallan \& Opstad (2014) found no relationship between personality traits and performance in accounting students but did when segregating genders.

With mixed results within the limited literature on personality and performance suggest an open relationship with no specific direction; this study explores the relationship between personality type and performance using a non-directional research question. 
RQ: What are the relationship between accounting students' extraversion, conscientiousness, openness, agreeableness, and neuroticism and performance as measured by final grade across face-to-face, hybrid, and online delivery modes?

\section{METHODOLOGY}

\section{Sample and Data Collection}

This study looks at the role of broad personality traits in education. Specifically, how the role of the broad big five personality traits may vary as a function with changes in educational delivery method. The data from this study comes from two senior-level accounting courses at a northeast regional public university: Auditing and Intermediate Accounting III each with a separate face-to-face, online, and hybrid section offering. The university has approximately 10,000 students of which approximately 575 are accounting majors. Seventy percent of the students attend on a full-time basis. We controlled the study by having the same professor teach the online, hybrid, and face-to-face courses in the same semester, using the same course materials (textbook, PowerPoint slides, assignments) and kept testing procedures consistent between sections. The university institutional review board approved this study.

One audit instructor was teaching each the online, traditional, and hybrid offerings for each course. Instructional delivery, course materials, evaluation assessments were consistent with each course across the three separate delivery formats. Students self-enrolled into sections representing one of the three different delivery methods. A traditional face-to-face instruction, no reduced contact hours, with supplemental materials posted online (syllabus, PowerPoint slides, etc.). The hybrid delivery format had $50 \%$ of the class meetings held online. The online format had $100 \%$ of the materials presented online with no scheduled class meeting times. All sections of the course had access to the online lecture videos, but only the hybrid and online sections were required to watch them. Course content was fairly consistent with delivery made being the only difference.

The students were given extra credit for voluntary participation in this study or an alternate assignment if they elected out of participation; none elected for the alternate assignment. Each respondent was assured the instructor would not have access to the information until after final grades posted, and each student completed the survey instrument in 20-30 minutes, over the course of two consecutive semesters. A combined total of 303 students participated in the two courses. There were 59 students enrolled in both courses with the same delivery method that were excluded, for a total of 210 unique instances, see Table 1. Data is divided by delivery method taken. 
TABLE 1

SAMPLE POPULATION

\begin{tabular}{|lccc|}
\hline & Audit & & Int. Acct. III \\
Completed Course & 165 & & 138 \\
Retaking Course & $(0)$ & & $(4)$ \\
Zero Average & $(1)$ & & $(0)$ \\
Did not participate & $(14)$ & & $(4)$ \\
Useable Responses & $\mathbf{1 5 0}$ & & $\mathbf{1 3 0}$ \\
Combined usable responses & & 280 & \\
Same student/same delivery method & & $(66)$ & \\
No GPA (Intelligence Measure) & & $(6)$ & \\
Deleted Residuals & & $(8)$ & \\
Useable for correlation and regression & & $\mathrm{N}=200$ & \\
& & & \\
$\quad$ Delivery Mode: & $\underline{\mathbf{T}}$ & $\underline{\mathbf{0}}$ & $\underline{\mathbf{H}}$ \\
$\quad$ Useable Responses & $\mathrm{n}=52$ & $\mathrm{n}=106$ & $\mathrm{n}=42$ \\
\hline
\end{tabular}

\section{Measurement}

Data was collected from each student's completion of the Abridged Big Five survey instrument, see Table 2. The abridged Big Five instrument was used in Antisnal et al. (2008; 2010). Using SSPS, means, standard deviations, correlational, and regression data were computed for all variables. Next, analysis of variance was computed to review differences in student performance, as measured by final grade, to individual personality traits and section delivery method. Results were not significant. 
TABLE 2

FIVE FACTOR MODEL OF PERSONALITY

\begin{tabular}{|c|c|c|c|c|c|c|c|c|c|c|}
\hline \multirow{4}{*}{ 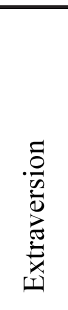 } & & & \multicolumn{2}{|c|}{$\begin{array}{r}\text { Traditional } \\
\text { Standard }\end{array}$} & Mean & $\begin{array}{l}\text { Online } \\
\text { Standard } \\
\text { Deviation }\end{array}$ & Mean & $\begin{array}{l}\text { Iybrid } \\
\text { Standard } \\
\text { Deviation }\end{array}$ & Mean & $\begin{array}{l}\text { Total } \\
\text { Standard } \\
\text { Deviation }\end{array}$ \\
\hline & E1 & I like to have a lot of people around me. & 3.35 & 0.95 & 3.20 & 0.93 & 3.27 & 0.97 & 3.25 & 0.94 \\
\hline & E2 & complete strangers. & 3.38 & 1.05 & 3.15 & 1.06 & 3.30 & 0.95 & 3.24 & 1.04 \\
\hline & E3 & I would rather be a leader of others. & 3.75 & 1.01 & 3.57 & 1.02 & 3.61 & 0.81 & 3.62 & 0.98 \\
\hline . & N1 & I am not a worrier. & 2.33 & 1.12 & 2.61 & 1.09 & 2.34 & 1.10 & 2.49 & 1.10 \\
\hline 晜 & $\mathrm{N} 2$ & I am seldom sad or depressed. & 2.98 & 1.20 & 3.09 & 1.24 & 3.11 & 1.19 & 3.07 & 1.21 \\
\hline $\bar{Z}$ & $\mathrm{~N} 3 *$ & wanted to hide. & 2.17 & 1.00 & 2.27 & 1.10 & 2.09 & 0.94 & 2.21 & 1.04 \\
\hline$\ddot{\delta}$ & $\mathrm{O} 1$ & I often try new and foreign foods. & 3.52 & 1.21 & 3.43 & 1.26 & 3.41 & 1.28 & 3.45 & 1.25 \\
\hline ฮี & $\mathrm{O} 2$ & abstract ideas. & 3.54 & 1.15 & 3.69 & 0.91 & 3.43 & 0.90 & 3.60 & 0.97 \\
\hline & $\mathrm{O} 3$ & and nature. & 3.58 & 1.00 & 3.54 & 1.01 & 3.59 & 0.97 & 3.56 & 1.00 \\
\hline n & A1 & I try to be courteous to everyone I meet. & 4.60 & 0.57 & 4.46 & 0.65 & 4.43 & 0.59 & 4.49 & 0.62 \\
\hline$\frac{\frac{\pi}{0}}{\frac{\pi}{\pi}}$ & $\mathrm{A} 2$ & $\begin{array}{l}\text { I would rather cooperate with others than } \\
\text { compete with them. }\end{array}$ & 4.02 & 0.75 & 3.86 & 0.99 & 3.70 & 1.00 & 3.87 & 0.94 \\
\hline$\stackrel{5}{0}_{\leftarrow}$ & A3 & $\begin{array}{l}\text { I don't like to get into arguments with my } \\
\text { family, friends, and co-workers. }\end{array}$ & 4.21 & 1.04 & 4.10 & 0.94 & 4.11 & 0.87 & 4.13 & 0.95 \\
\hline$\tilde{z}$ & $\mathrm{C} 1 *$ & I am not a very methodical person. & 2.65 & 1.03 & 2.61 & 0.93 & 2.73 & 0.85 & 2.64 & 0.93 \\
\hline.$\stackrel{0}{0}$ & $\mathrm{C} 2 *$ & $\begin{array}{l}\text { I never seem to be able to get organized. } \\
\text { I find it hard to keep my belongings clean }\end{array}$ & 2.23 & 0.98 & 2.13 & 1.05 & 2.14 & 0.93 & 2.16 & 1.01 \\
\hline $\begin{array}{l}\cdot \frac{0}{0} \\
0 \\
0 \\
0\end{array}$ & $\mathrm{C} 3 *$ & $\begin{array}{l}\text { and neat. } \\
\text { I waste a lot of time before settling down to }\end{array}$ & 2.23 & 0.94 & 2.19 & 1.13 & 2.23 & 0.96 & 2.21 & 1.05 \\
\hline & $\mathrm{C} 4 *$ & work. & 3.19 & 1.03 & 2.62 & 1.15 & 3.02 & 1.15 & 2.85 & 1.14 \\
\hline & & $\begin{array}{l}\text { * Reverse Questioned } \\
5 \text { Point Likert Scale; } 1=\text { Strongly Disagree, }\end{array}$ & 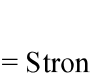 & Agree & & & & & & \\
\hline
\end{tabular}

\section{Variables}

The personality assessment instrument used was an abbreviated 16-item version of the Big Five inventory (Antisnal et al., 2010; Antisnal et al., 2008). The Big Five was used to measure students' selfreported levels of OCEAN. For each of these questions students rated their answers using a 5 point Likert scale $1=$ strongly disagree, $2=$ disagree, $3=$ neutral, $4=$ agree $5=$ strongly agree. Individual items were summed then averaged to create an overall measure of each personality characteristic.

Courses segregated into three categories by assigned face-to-face meeting times between instructor and student. Traditional classes did not meet online; only supplemental materials were available (e.g., syllabus, review questions, study guides). The hybrid course met $50 \%$ online, and the online class had no face-to-face meetings assigned. All three-delivery methods had access to prerecorded lectures, but only the hybrid and online groups were required to use them. The performance measured by final numerical grades the students received in the course. Data was collected from each instructor's final grade calculations as reported to the registrar. 


\section{RESULTS}

Five multiple regressions were run to predict relationships between academic performance (final grade) in online, face-to-face, and hybrid delivery modes on the Big Five personality factors. There was linearity as assessed by partial regression plots and a plot of studentized residuals against the predicted values. There was the independence of residuals, as assessed by a Durbin-Watson static less than 2 for each mode. There was homoscedasticity, as assessed by variance inflation factor values less than 2 in all modes. There was no evidence of multicollinearity, as assessed by tolerance values greater than 0.1 . Studentized residuals greater than + or -3 standard deviations were deleted, no leverage values greater than 0.2 , and values for Cook's distance above 1 . The assumption of normality met, as assessed by a Q-Q Plot. Standardized coefficient, t-values, F-values, $R^{2}$, and adjusted $R^{2}$ can all be found in Tables 3 and 4 .

\section{TABLE 3}

\section{MULTIPLE REGRESSION RESULTS WITH BIG FIVE REGRESSION ON DELIVERY MODES}

\begin{tabular}{|c|c|c|c|c|c|c|c|c|c|c|c|c|}
\hline \multirow[b]{2}{*}{ Variables: } & \multicolumn{4}{|c|}{ Model 1: Traditional } & \multicolumn{4}{|c|}{ Model 2: Online } & \multicolumn{4}{|c|}{ Model 3: Hybrid } \\
\hline & Mean & B & $\mathrm{t}$ & Sig. & Mean & B & $\mathrm{t}$ & Sig. & Mean & B & $\mathrm{t}$ & Sig. \\
\hline Final Grade & 83.39 & & 3.171 & & 85.54 & & 9.707 & & 87.00 & & 5.487 & \\
\hline Extraverted & 3.49 & -0.004 & -0.032 & 0.975 & 3.33 & 0.183 & 1.719 & 0.089 & 3.40 & 0.153 & 1.039 & 0.306 \\
\hline Not Neurotic & 3.04 & -0.041 & -0.330 & 0.743 & 3.19 & -0.189 & -1.904 & 0.060 & 3.15 & -0.227 & -1.540 & 0.133 \\
\hline Openness & 3.54 & 0.096 & 0.766 & 0.448 & 3.57 & 0.043 & 0.417 & 0.677 & 3.52 & -0.116 & -0.752 & 0.457 \\
\hline Agreeableness & 4.28 & -0.052 & -0.408 & 0.685 & 4.15 & -0.054 & -0.535 & 0.594 & 4.09 & 0.184 & 1.163 & 0.253 \\
\hline Consciousness & 3.42 & 0.241 & 1.965 & 0.056 & 3.61 & 0.003 & 0.032 & 0.975 & 3.46 & 0.095 & 0.590 & 0.590 \\
\hline GPA & 3.20 & 0.639 & 5.046 & $>.001 * * *$ & 3.20 & 0.256 & 2.649 & $.009 * *$ & 3.25 & 0.352 & 2.262 & $0.03 *$ \\
\hline Gender & 0.365 & 0.025 & 0.198 & 0.844 & 0.509 & 0.079 & 0.767 & 0.445 & 0.45 & 0.044 & 0.262 & 0.795 \\
\hline $\mathrm{F}$ & & $19^{* * *}$ & & & & 2.034 & & & & $2.326^{*}$ & & \\
\hline $\mathrm{R}^{2}$ & & 0.418 & & & & 0.127 & & & & 0.324 & & \\
\hline Adjusted $\mathrm{R}^{2}$ & & 0.326 & & & & 0.064 & & & & 0.185 & & \\
\hline $\mathrm{N}$ & & 52 & & & & 106 & & & & 42 & & \\
\hline $\begin{array}{l}* \text { Correlation i } \\
* * \text { Correlation } \\
* * * \text { Signficant }\end{array}$ & $\begin{array}{l}\text { signifi } \\
\text { is signi } \\
\text { at the } 0\end{array}$ & $\begin{array}{l}\text { cant at } t \\
\text { icant at } \\
001 \text { lev }\end{array}$ & $\begin{array}{l}0.05 \\
\text { the } 0.01 \\
\text { (2-tai }\end{array}$ & $\begin{array}{l}\text { vel }(2-t a \\
\text { evel }(2-t\end{array}$ & & & & & & & & \\
\hline
\end{tabular}

None of five personality traits had significant results in any delivery mode suggesting personality does not impact performance. Extraversion had a negative relationship in traditional delivery modes, and a positive in online delivery. Neither of these was significant. Conscientiousness had a positive relationship in all delivery modes but was not statistically significant. Factorial ANOVA's were run where the final grade was the dependent variable with no significant differences in any delivery mode. Consistent with prior literature GPA was a statistically significant predictor of performance (final grade) in all delivery modes and in both the audit and intermediate courses. There were no significant differences separating the two courses by delivery mode so they are presented to together.

\section{DISCUSSION}

This study looked at the role of personality traits in various educational delivery methods. In doing this, we attempted to identify predictors of academic success in one delivery mode as compared to another based on the non-cognitive personality traits using the Big Five. No individual Big Five factors significantly predicted positive academic performance see Tables 3 and 4 . This is inconsistent with the literature on consciousness which has been a significant predictor in all levels of education and strengthens in higher education is conscientiousness. In the regression analysis, GPA was significant, in 
all models. This is consistent with prior literature suggesting that good performing students perform well regardless of delivery mode. There were no personality traits that were significant in any model. When looking at Pearson' correlations, GPA and consciousness were significant at the .01 and .05 levels respectively (2-tailed), and interactions between other variables are mixed, see Table 5.

TABLE 4

MULTIPLE REGRESSION RESULTS WITH BIG FIVE REGRESSION ON COURSES

\begin{tabular}{|c|c|c|c|c|c|c|c|c|}
\hline \multirow[b]{2}{*}{ Variables: } & \multicolumn{4}{|c|}{ Audit } & \multicolumn{4}{|c|}{ Intermediate III } \\
\hline & Mean & $\mathrm{B}$ & $\mathrm{t}$ & Sig. & Mean & $\mathrm{B}$ & $\mathrm{t}$ & Sig. \\
\hline Final Grade & 85.59 & & 11.339 & & 87.586 & & 7.669 & \\
\hline Not Neurotic & 3.37 & 0.157 & 1.867 & 0.064 & 3.359 & 0.042 & 0.467 & 0.641 \\
\hline Extraverted & 3.16 & -0.039 & -0.480 & 0.632 & 3.192 & -0.118 & -1.388 & 0.168 \\
\hline Openness & 3.54 & 0.059 & 0.691 & 0.491 & 3.567 & -0.006 & -0.071 & 0.943 \\
\hline Agreeableness & 4.18 & 0.048 & 0.577 & 0.565 & 4.161 & -0.042 & -0.509 & 0.611 \\
\hline Consciousness & 3.49 & 0.019 & 0.217 & 0.828 & 3.611 & 0.147 & 1.733 & 0.086 \\
\hline GPA & 3.21 & 3.667 & 3.667 & $>.001 * * *$ & 3.24 & 0.497 & 6.186 & $001 * * *$ \\
\hline Gender & 0.469 & 0.917 & 0.917 & 0.361 & 0.477 & 0.019 & 0.223 & 0.824 \\
\hline $\mathrm{F}$ & 3.167 & & & & 6.455 & & & \\
\hline $\mathrm{R}^{2}$ & 0.139 & & & & 0.274 & & & \\
\hline Adjusted $\mathrm{R}^{2}$ & 0.095 & & & & 0.231 & & & \\
\hline $\mathrm{N}$ & 145 & & & & 128 & & & \\
\hline
\end{tabular}

TABLE 5

PEARSON'S CORRELATIONS

\begin{tabular}{|c|c|c|c|c|c|c|c|c|}
\hline \multirow[b]{2}{*}{ Variables } & \multicolumn{5}{|c|}{ Final } & \multirow[b]{2}{*}{$\underline{\text { Not Neurotic }}$} & \multirow[b]{2}{*}{ Openness } & \multirow[b]{2}{*}{ Agreeable } \\
\hline & M & SD & $\overline{\text { Grade }}$ & $\underline{\text { GPA }}$ & Extravert & & & \\
\hline Final Grade & 85.314 & 6.927 & & & & & & \\
\hline GPA & 3.210 & 0.397 & $0.382 * * *$ & & & & & \\
\hline Extraverted & 3.386 & 0.781 & 0.097 & 0.015 & & & & \\
\hline Not Neurotic & 3.142 & 0.693 & -0.059 & 0.041 & $0.202 * *$ & & & \\
\hline Openness & 3.551 & 0.829 & 0.001 & -0.053 & $0.216^{* * *}$ & 0.011 & & \\
\hline Agreeableness & 4.170 & 0.594 & 0.052 & 0.048 & $0.134^{*}$ & $0.147^{*}$ & -0.044 & \\
\hline Consciousness & 3.532 & 0.747 & $0.149^{*}$ & 0.107 & $0.116^{*}$ & 0.064 & $0.13 *$ & $0.237 * * *$ \\
\hline \multicolumn{9}{|c|}{$\begin{array}{l}* \text { Correlation is significant at the } 0.05 \text { level }(2 \text {-tailed). } \\
* * \text { Correlation is significant at the } 0.01 \text { level }(2 \text {-tailed). } \\
* * * \text { Correlation is significant at the } 0.001 \text { level (2-tailed). } \\
\mathrm{N}=200\end{array}$} \\
\hline
\end{tabular}




\section{CONCLUSIONS AND RECOMMENDATIONS}

\section{Conclusion}

Personality is unique to each and plays a role in the learning process. Varella, Carter, and Michel (2012) assert online, and hybrid delivery formats require different student behaviors than face-to-face. Students possess traits adaptable to various delivery methods and instructor differences. Consistent with prior literature, students with high GPA's performed better across all delivery modes. Most notable was the results in consciousness were not predictors for success in any delivery modes. Hybrid delivery is suggested to have the flexibility of a mixed platform that allows those high introversion students a platform to perform while having time to reflect independently on the information and also allowing for the instructor-student interaction in the classroom. Given the nature of online education, we expect the introversion online match to strengthen the individual student performance as determined by final grade but it did not. This could be reviewed further in future studies.

\section{Limitations}

There are several limitations to this study. First, the participants represent that of a local New England teaching university. The results may be different if conducted in a research university, or in another geographical region. Another limitation is that students self-selected into the course delivery mode. If students were randomly assigned the results may have been different especially in areas such as agreeableness as a student may not have been as open to an alternative learning format. Larger sample sized in the face-to-face and hybrid delivery may yield different results.

\section{Implications and Future Research}

The purpose of this research was to explore the relationship between personality types and performance in accounting classes across various delivery modes. Previous studies have shown best practices in face-to-face education in regard to engaging the attention of students. This is new in hybrid and online courses and represents an important knowledge gap. As alternative course formats develop, knowing best practices for instructors and students is even more important. This study addresses this literature gap by testing the role of personality traits across traditional, online, and hybrid instructional delivery methods. Knowing which personality traits encourage learning in different delivery modes can help advise students in selecting course delivery modes that best suit them.

Future research could extend off this study to determine if there is any relationship between conscientiousness and work drive and-or general intelligence in expanded populations and other geographic regions. The study could also be segregated using various student demographics such as age, gender, race, etc. Performance could also be looked at in regard to exam average, as final grades incorporated other skills required of projects and other assignments. Gender variances were looked at but were not significant and could be expanded for further analysis. 


\section{REFERENCES}

Allport, G. W. and Odbert, H. S. (1936). Trait names: A psycho-lexical study. Psychological Monographs, 47 (1, whole No. 211).

Allen, I. E. \& Seaman J. (2017). Digital learning compass: Distance education enrollment report 2017. Babson Survey Research Group. Digital Learning Compass: e-Literate. WICHE Cooperative for Educational Technologies. Retrieved from: onlinelearningsurvey.com

Allen, I. E. \& Seaman J. (2016). Online Report Card: Tracking Online Education in the United States. Babson Survey Research Group and Quahog Research Group, LLC. Retrieved from: onlinelearningsurvey.com

Anitsal, M. M., Anitsal, I., Barger, B., Fidan, I., \& Allen, M. R. (2010). Achieving quality enhancement program (QEP) objectives: Impact of on-line and on-ground course characteristics by undergraduate student personality traits. Academy of Educational Leadership Journal, 14(1), 3754.

Anitsal, M. M., Anitsal, I., Barger, B., Fidan, I., \& Allen, M. R. (2008). Student evaluations of course attributes of online courses versus on-ground courses: Impact of student personality traits. Allied Academies International Conference, 13(1), 1-8.

Chen, C. C., Jones, K. T., \& Moreland, K. A. (2012). Online accounting education versus in-class delivery: Does course level matter?. Issues in Accounting Education, 28(1), 1-16.

Colorado, J. T. \& Eberle, J. (2010). Student demographics and success in online learning environments. Emporia State Research Studies, 46(1), 4-10.

Daisley, R. J. (2011). Considering personality type in adult learning: Using the Myers-Briggs type indicator in instructor preparation at PricewaterhouseCoopers. Performance Improvement, 50(2), 15-24. doi:10.1002/pfi.20196

Fallan, L., \& Opstad, L. (2014). Beyond gender performance in accounting: does personality distinction matter?. Accounting Education, 23(4), 343-361.

Farrington, C. A., Roderick, M., Allensworth, E., Nagaoka, J., Keyes, T. S., Johnson, D. W., and Beechum, N. O. (2012). Teaching adolescents to become learners. The role of noncognitive factors in shaping school performance: A critical literature review. Chicago: University of Chicago Consortium on Chicago School Research.

Figlio D., Rush M., \& Yin L. (2010). Is it live or is it internet? Experimental estimates of the effects of online instruction on student learning. National Bureau of Economic Research Working Paper 16089, June 2010.

Harrington, R. \& Loffredo, D. A. (2010). MBTI personality type and other factors that relate to preference for online versus face-to-face instruction. Internet and Higher Education, 13, p. 89-95. doi: 10.1016/j.iheduc.2009.11.006

Holland, J. L. (1997). Making Vocational Choices: A Theory of Vocational Personalities and Work Environments. Lutz, FL: Psychological Assessment Resources.

Huh, S., Jin, J. J., Lee, K. J., \& Yoo, S. (2010). Differential effects of student characteristics on performance: Online vis-a-vis offline accounting courses. Academy of Educational Leadership Journal, 14(4), p. 81-89. Retrieved from http://search.proquest.com/docview/763259454?accountid=14872

Jung, C. G. (1976). Psychological Types (The Collected works of C. G. Jung, Vol. 6). Adler, G. \& Hull, R. F. C. (Eds. and Trans.). Princeton, NJ: Princeton University Press.

Kolb, D. A. (2014). Experiential learning: Experience as the source of learning and development. FT press.

McCrae, R. R., \& Costa, P. T, Jr. (1989). Reinterpreting the Myers-Briggs type indicator from the perspective of the five-factor model of personality. Journal of Personality 57(1). p. 17-40. doi: 10.1111/j.1467-6494.1989.tb00759.x

McCrae, R. R., \& John, O. P. (1992). An introduction to the five-factor model and its applications. Journal of Personality, 60(2). P. 175-215. doi: 10.111/j1467-6494-1992-tb00970.x 
Poropat, A. E. (2009). A meta-analysis of the five-factor model of personality and academic performance. Psychological Bulletin, 135(2). 322-228. doi: 10.1037/a0014996

Pringle, C. D., Dubose, P. B., \& Yankey, M. D. (2010). Personality characteristics and choice of academic major: are traditional stereotypes obsolete?. College Student Journal, 44(1), 131-142.

Seiver, J., \& Troja, A. (2014). Satisfaction and success in online learning as a function of the needs for affiliation, autonomy, and mastery. Distance Education, 35(1), 90-105. doi:10.1080/01587919.2014.891427

Taggar, S. \& Parkinson, J. (2007). Personality tests in accounting research. Journal of Human Resource Costing \& Accounting, 11(2). P. 122-151. Doi: 10.1108/14013380710778776

Tidwell, M. V., Southard, S., \& Mooney, M. (2010). Assessing the role of personality traits in student performance in traditional, hybrid and online classes. International Journal of Education Research, 5(2), 69-84.

U.S. Department of Commerce. (2013). Exploring the digital nation: America's emerging online experience. Washington, D.C. Retrieved from http://www.ntia.doc.gov/files/ntia/publications/exploring_the_digital_nation__americas_emerging_online_experience.pdf.

U.S. Department of Education Office of Planning, Evaluation, and Policy Development. (2009). Evaluation of evidence-based practices in online learning: A meta-analysis and review of online learning studies. Washington, D.C. Retrieved from https://www2.ed.gov/rschstat/eval/tech/evidence-based-practices/finalreport.pdf

Varella, O, Carter, J. J. III, \& Michel, N. (2012). Online learning in management education: An empirical study of the role of personality traits. Journal of Computing in Higher Education, 24, p. 209-225. doi: $10.1007 / \mathrm{s} 12528-012-9059-\mathrm{x}$

Wheeler, P. (2001). The Myers-Briggs Type Indicator and applications to accounting education and research. Issues in Accounting Education, 16(1). P. 125-150. Doi: http://dx.doi.org/10.2308/iace.2001.16.1.125

Xu, D, \& Jaggars, S. S. (2014). Performance gaps between online and face-to-face courses: Differences across types of students and academic subject areas. Journal Of Higher Education, 85(5), 633659. 